\title{
Special Series "Heart Failure in the Young and Old: Insights into Various Therapies"
}

\author{
Roland Hetzer \\ Department of Cardiothoracic and Vascular Surgery, Cardio Centrum Berlin, Berlin, Germany \\ Correspondence to: Roland Hetzer. Department of Cardiothoracic and Vascular Surgery, Cardio Centrum Berlin, Berlin, Germany. \\ Email: roland.hetzer@gmail.com.
}

Submitted Sep 27, 2020. Accepted for publication Oct 10, 2020.

doi: 10.21037/cdt-2020-hfyo-19

View this article at: http://dx.doi.org/10.21037/cdt-2020-hfyo-19

It is with great appreciation that a Special Series issue in and by this prestigious journal of Cardiovascular Diagnosis and Therapy has been allotted as a platform to impart condensed scientific and medical researches, reviews and reports focused on particular topics, of which being concentrated on one issue, would provide substantial insights and perspectives.

This is a special series focused on various treatment strategies in heart failure. Chronic heart failure is presently the most prevalent heart pathology complex, primarily because of its increasing incidence with an ever-aging population. This could be attributed to successful treatment of acute heart failure by interventional, operative, or instrumental interventions, thus delaying death to a later time. Such aforementioned interventions do not solely apply to the adult population with heart failure but also to newborns, infants and children with congenital heart diseases, who, through interventions, can reach adolescence and/or even adulthood until the "still somewhat" abnormal circulation comes to its functional limits.

In this special series, we have compiled a number of treatment alternatives of heart failure, ranging from advances in conservative and surgical therapy, i.e., medical concepts over new types of catheter interventions and the application of artificial pumps (Figure 1) to assist or replace the failing heart function and its potential to allow functional restoration until the utmost treatment, i.e., heart transplantation in adults and in children with its limitations and possibilities (Figure 2).

This collection may not be complete; however, the demonstration of some of the newer techniques and insights may stimulate the interested reader to contemplate over

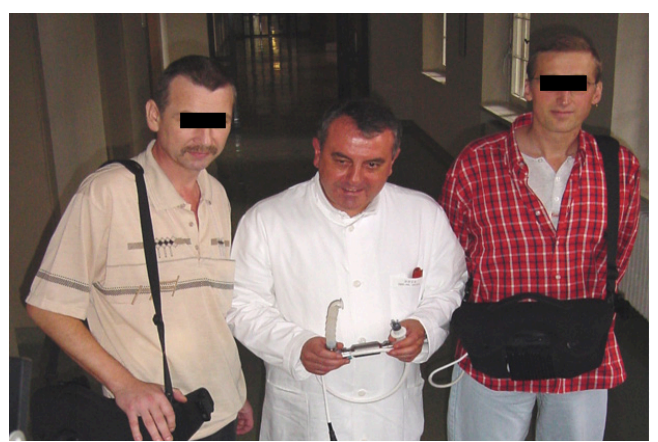

Figure 1 The first two patients implanted with a ventricular assist device (Berlin Heart INCOR, Germany) by Prof. Hetzer in 2002.

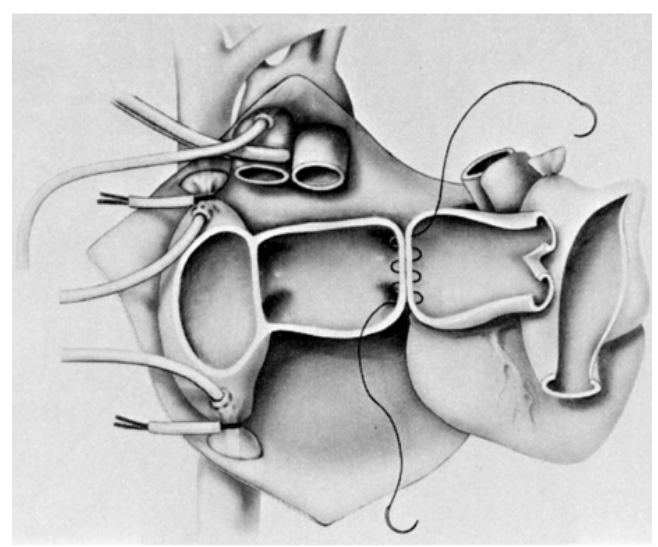

Figure 2 Graphical illustration of a biatrial anastomosis technique in orthotopic heart transplantation.

their own ideas and suggestions and that they would be able to perceive the present boundaries of knowledge in this field. 


\section{Acknowledgments}

I appreciate the assistance of Dr. Eva Maria Javier Delmo in preparing this editorial.

Funding: None.

\section{Footnote}

Provenance and Peer Review: This article was commissioned by the editorial office, Cardiovascular Diagnosis and Therapy for the series "Heart Failure in the Young and Old: Insights into Various Therapies". The article did not undergo external peer review.

Conflicts of Interest: The author has completed the ICMJE uniform disclosure form (available at http://dx.doi. org/10.21037/cdt-2020-hfyo-19). The series "Heart Failure in the Young and Old: Insights into Various Therapies" was commissioned by the editorial office without any funding or sponsorship. RH served as the unpaid Guest Editor of the series and serves as an unpaid editorial board member of Cardiovascular Diagnosis and Therapy from July 2019 to Jun 2021. The author has no other conflicts of interest to declare.

Ethical Statement: The author is accountable for all aspects of the work in ensuring that questions related to the accuracy or integrity of any part of the work are appropriately investigated and resolved.

Open Access Statement: This is an Open Access article distributed in accordance with the Creative Commons Attribution-NonCommercial-NoDerivs 4.0 International License (CC BY-NC-ND 4.0), which permits the noncommercial replication and distribution of the article with the strict proviso that no changes or edits are made and the original work is properly cited (including links to both the formal publication through the relevant DOI and the license). See: https://creativecommons.org/licenses/by-nc-nd/4.0/.

Cite this article as: Hetzer R. Special Series "Heart Failure in the Young and Old: Insights into Various Therapies". Cardiovasc Diagn Ther 2021;11(1):146-147. doi: 10.21037/cdt2020-hfyo-19 